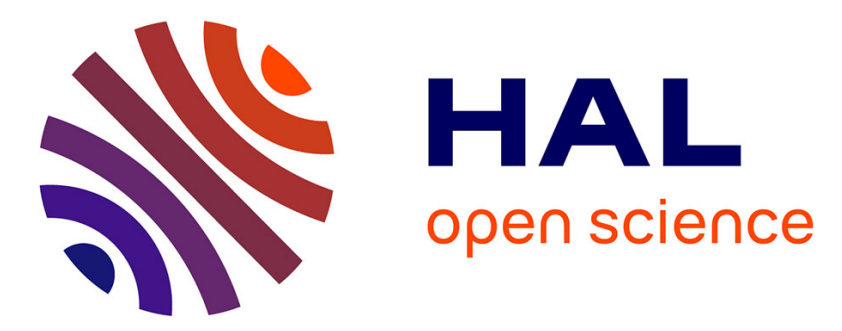

\title{
CROSS-LINKED ACTIN NETWORKS (CLANs) ARE PRESENT IN LAMINA CRIBROSA CELLS.
}

Raly Job, Vignesh Raja, Ian Grierson, Laura Currie, Steven O'Reilly, Natalie Pollock, Emma Knight, Abbot F Clark

\section{- To cite this version:}

Raly Job, Vignesh Raja, Ian Grierson, Laura Currie, Steven O'Reilly, et al.. CROSS-LINKED ACTIN NETWORKS (CLANs) ARE PRESENT IN LAMINA CRIBROSA CELLS.. British Journal of Ophthalmology, 2010, 94 (10), pp.1388. 10.1136/bjo.2009.176032 . hal-00563606

\section{HAL Id: hal-00563606 https://hal.science/hal-00563606}

Submitted on 7 Feb 2011

HAL is a multi-disciplinary open access archive for the deposit and dissemination of scientific research documents, whether they are published or not. The documents may come from teaching and research institutions in France or abroad, or from public or private research centers.
L'archive ouverte pluridisciplinaire HAL, est destinée au dépôt et à la diffusion de documents scientifiques de niveau recherche, publiés ou non, émanant des établissements d'enseignement et de recherche français ou étrangers, des laboratoires publics ou privés. 


\section{CROSS-LINKED ACTIN NETWORKS (CLANS) ARE PRESENT IN LAMINA CRIBROSA CELLS.}

Raly Job ${ }^{1,2}$

Vignesh Raja ${ }^{1}$

Ian Grierson ${ }^{1}$

Laura Currie ${ }^{1}$

Steven O'Reilly ${ }^{1}$

Natalie Pollock ${ }^{1}$

Emma Knight ${ }^{1}$

Abbot F. Clark ${ }^{3}$

${ }^{1}$ Unit of Ophthalmology and St Pauls Eye Unit, School of Clinical Sciences, University of Liverpool, Liverpool, UK.

${ }^{2}$ Eye care centre, Leighton Hospital, Crewe, UK.

${ }^{3}$ Department of Cell Biology \& Anatomy and the North Texas Eye Research Institute, University of North Texas Health Science Center, Ft. Worth, TX, USA.

Key words: lamina cribrosa, actin, CLANs, trabecular meshwork, dexamethasone

Word count: 2944

Corresponding author:

Raly Job

Glaucoma Fellow

Eye care centre, Leighton Hospital

Crewe, UK, CW1 4QJ

Tele: 00441517064912

Mob: 00447903826245

Fax: 00441517065934

Email: ralyjob@gmail.com

Competing Interest: None to declare. 
Licence for Publication:

"The Corresponding Author has the right to grant on behalf of all authors and does grant on behalf of all authors, an exclusive licence (or non exclusive for government employees) on a worldwide basis tothe BMJ Publishing Group Ltd and its Licensees to permit this article (if accepted) to be published in BJO editions and any other BMJPGL products to exploit all subsidiary rights, as set out in our licence (http://group.bmj.com/products/journals/instructions-for-authors/licence-forms/)." 


\section{ABSTRACT}

Aims: A study was undertaken to determine and compare the F-actin staining patterns in the cells of the lamina cribrosa (LC) of normal, Dexamethasone (DEX) treated and glaucomatous dissected tissue and cell cultures.

Methods: Around 30 dissected donor eyes and 9 cell lines provided the human specimens and 25 eyes and 20 primary cell cultures provided the bovine material. Appropriate samples were exposed to $10^{-7} \mathrm{M}$ DEX for up to 14 days. LC tissue and cells were stained with Phalloidin-Alexa 488 to identify F-actin and all samples were examined by confocal or epifluorescent microscopy.

Results: Both in the LC tissue and LC cell cultures the dominant actin arrangement was bundles of stress fibres. However cross-linked actin networks (CLANs) were identified in the tissue and in culture. These were markedly increased by steroid treatment and were particularly large and abundant in cultures from glaucoma donors. CLANs were not associated with optic nerve head astrocytes (ONHAs).

Conclusions: The presence of abundant stress fibres in situ and in vitro highlights the biomechanical contribution of LC cells. However that we have identified CLANs in these cells shows that they are not exclusive to the trabecular meshwork, the only other place they have been found, and may have a role in glaucoma pathology.

\section{INTRODUCTION}

The importance of tissue biomechanics and stretch has been of considerable research interest in both the trabecular meshwork(TM)[1-3] of the aqueous outflow system and the lamina cribrosa (LC)[4-7] of the optic nerve head both with respect to normal function, drug action and also to glaucoma. Of key importance is the nature and architectural arrangement of the extracellular matrix (ECM) proteins plus the distribution of the constituent cells and their cytoskeletal organisation. The cytoskeleton, particularly the role and distribution of actin microfilaments, has been the subject of much detailed research in the TM[3,8-10] but that has not been the case for cells of the LC, despite the reported similarities between TM and LC cells.[11]

The F-actin in TM cells is distributed in thick bundles called stress fibres[3,8-10] that have a role in cellular contractility and are remodelled by stretch.[3,12] However TM cells also exhibit polygonal actin arrangements that are more abundant after steroid treatment $[9,13]$ and are prevalent in the glaucomatous TM.[10] The polygonal arrangements, called cross-linked actin networks or CLANs,[13] are poorly understood but their formation may be the harbinger of the adverse and pathological cellular events $[9,10]$ that occur in glaucoma.

Surrounding and embedded within the septae of the LC in the optic nerve head are cells that are rich in F-actin.[14] The effects of elevated intraocular pressure on optic nerve head cell shape and F-actin distribution have been reported $[15,16]$ as has the actin distribution in the nerve fibre layer of an animal model of glaucoma,[17] but little emphasis has been placed on the basic types of F-actin patterns in cells of the LC either in health or glaucoma. In this study, we used confocal microscopy to investigate the actin distribution of human and bovine LC cells in situ and in monolayer culture in vitro with particular emphasis on whether CLANs are associated with normal and glaucomatous LC cells and can be up-regulated by dexamethasone (DEX). Prior to our current research, CLANs have 
been considered to be exclusive to the TM tissue $[9,10]$ and to TM cells in culture as shown by Clark [13] who tested various cell types including retinal pigment epithelium, lens epithelium and bovine coronary artery vascular endothelium. We report that this is no longer the case and believe it may have implications for the cellular understanding of glaucoma.

\section{MATERIALS AND METHODS}

The optic nerve head and LC region was dissected from formalin fixed human donor eyes provided by eye banks both in the UK and the USA and over 30 were provided. These were all from elderly individuals ranging in age from 63 to 98; with an average of 78 years. Four of the eyes were from donors with primary open angle glaucoma. Bovine eyes ( 25 were used for this study) were obtained from a local abattoir and fixed in the same manner as the human tissue. All dissections were done using a BM1 Long Arm Stereomicroscope and appropriate tissue was taken for conventional wax histology, cryosectioning (2800 Frigocut-E Cryostat;Leica Microsystems) and whole mount examination of segments of the LC as with previous work.[15] Microscopic examination was conducted by light microscopy, phase microscopy, immuno-fluorescent microscopy (staining described later) and confocal microscopy.

Both normal (established from 5 different donors) and glaucomatous (established from four different donors) human lamina cribrosa (HLC) cells were available to us for our investigations. Bovine lamina cribrosa (BLC) cells were grown and characterized as previously reported $[5,18,19]$ and the optic nerve tissue of at least 20 eyes were grown from primary cultures. BLC cells in culture were similar to HLC cells in appearance[18] and were unaltered by varying serum levels.

Cellular morphology was monitored using phase microscopy at magnification of $x 40$ and $x 60$. Dye exclusion using trypan blue (Sigma) was used routinely to check cell viability while propidium iodide (PI) was used to check nuclear size and condition.

\section{Dexamethasone (DEX) Experiments}

LC tissue from dissected human and bovine optic nerve heads and cultured cells from the LC of both species were treated with DEX. For the cell culture experiments, $L C$ cell monolayers were grown to confluence on 4 well Nunc ${ }^{T M}$ Lab-Tek $^{T M}$ Chamber slides ${ }^{T M}$. A concentration of $10^{-7} \mathrm{M}$ DEX was chosen for all experiments which is the optimum corticosteroid level that produces maximum CLAN numbers in TM cells. $[9,10,20]$ Experiments were conducted with control, vehicle groups given $0.1 \%$ ethanol and experimental groups exposed to DEX up to 14 days with change of media every other day.

Following appropriate treatment, cells were fixed in $10 \%$ neutral buffered formalin for 10 minutes. Both cell culture and dissected tissue samples were then stained with phalloidin-Alexa 488 (Molecular Probes Europe, The Netherlands) diluted in PBS containing 0.1\% Tween-20 to 1:20 and 1:40 respectively, for a maximum of 40 minutes and in half our experimental runs, nuclei were stained with PI for 15 minutes. Fluorescence Mounting Medium (DakoCytomation, U.K.) was added to the slide, which were then covered by an appropriate coverslip. When required, immune fluorescent staining for alpha-actinin was performed as described.[9]

Additional experiments were conducted which were designed to determine whether DEX-induced CLANs were stable and present after DEX removal from the medium. BLC cells were exposed to DEX 
for 10 days, and then the cells were examined at various times up to 10 days following DEX withdrawal. The cells were fixed and stained with phalloidin-Alexa 488 and PI and imaged as described.

\section{Microscopy and Image Analysis}

For routine qualitative evaluation, images were obtained by conventional epifluorescence microscopy using a Nikon Optiphot microscope and detailed analysis was conducted with an MRC600 confocal laser scanning microscopy-imaging system (Bio-Rad UK). Images were captured using either $x 40$ or $x 60$ objectives and was taken as single image or a z-series was created. Z-series allowed us to examine the cell staining patterns in more detail as we could have virtual sections through the sample, especially useful for dissected tissue. The Z-series used routinely extended 10$11 \mu \mathrm{m}$ in depth (11 images with $1 \mu \mathrm{m}$ spacing between each).

CLAN counting was undertaken on previously masked slides. Counts were made of the number of CLANs and number of nuclei per image. A total of 25 fields were photographed per well so that we had 100 fields for analysis for each slide under investigation. Each experiment was repeated at least 3 times. All images were analysed initially using confocal assistant (version 4) and then Aequitas IDA software (1.3, DDL Ltd, UK).

\section{RESULTS}

\section{Tissue}

Low power fluorescent imaging of frozen sagittal-sections of the human optic nerve head shows areas of intense phalloidin-Alexa 488 staining associated with the central retinal vessels but also with the whole of the LC region (Fig.1a). The majority of the cells located within and around the connective-tissue laminae stained intensely for F-actin. In the LC, the strong actin staining is orientated predominantly at right angles to the post laminar nerve fibre bundles. Bright fluorescent streaks and dots were present, which coincided with PI staining (Fig.1b).

Careful examination of the cells within and around the connective tissue of the $\mathrm{LC}$ revealed a diffuse pattern of phalloidin-Alexa 488 staining in the cytoplasm of the whole cell population. At higher magnification individual cells in the LC septae were seen to have prominent stress fibres that stood out from the diffuse background staining in the cytoplasm. The stress fibres formed complex patterns and arrangements but the most pronounced arrangement was of stress fibre bundles that ran parallel to the long axes of the cell (Fig.2a). These fibres could be up to $0.5 \mu \mathrm{m}$ in thickness and extend the whole length of the cells from the LC (up to about $25 \mu \mathrm{m}$ ), with most fibres in the 8 to $15 \mu \mathrm{m}$ range.

Frequently we found actin-rich structures that were more focally organised measuring from 2 to $8 \mu \mathrm{m}$ in diameter. Bright fluorescent actin spots that connected to fluorescent strands were noted quite often within the cells of the LC region, but interestingly they were not seen elsewhere. These structures did have an arrangement similar to the hubs and spokes that characterise CLANs of the TM. Following exposure to DEX, the focal arrangements with CLAN-like features appeared to be more prominent in the cells of the LC region (Fig. $2 \mathrm{~b}$ ). Some of the focal aggregates were less clearly CLAN-like based on phalloidin staining alone but these foci were seen as an intense aggregate of 
fluorescent dots when stained for alpha-actinin (Fig.2C). As the hub points in CLANs are known to be both F-actin and alpha-actinin positive [13] this was more re-assuring.

Similar findings of diffuse cytoplasmic actin staining, prominent stress fibres and focal actin aggregates were found in the LC of bovine optic nerve tissue with and without DEX exposure (data not shown).

\section{Cell Culture}

Optic nerve head astrocytes (ONHAs) are found to be GFAP positive while LC cells are GFAP negative.[18] These cells were grown from both human and bovine specimens in monolayer culture. The appearance of the cells from both species conformed to that described in the literature,[18] with the LC cells being broad and flattened, whereas the ONHAs were more stellate or kite-shaped with prominent processes. The BLC cells were generally smaller in surface area and maximum diameter compared to the HLC cells, but otherwise they are very similar in appearance. The bovine ONHAs tended to grow faster and sub cultured more effectively and reliably than the human cells. Typically the human ONHAs grew rather poorly in our standardised tissue culture conditions.

Most of the F-actin staining was carried out on the LC cells, but both cell types had abundant stress fibre bundles in their cytoplasm. The larger LC cells showed more prominent stress fibres (Fig 3a) compared to ONHAs which had finer, more delicate stress fibres (not shown). Confluent BLC cells and ONHAs were examined for CLANs, and a minority of BLC cells (up to $6 \%$ of cells in some cultures) had distinctive CLAN arrangements in their cytoplasm, which were absent in the ONHAs. Exposure of the ONHAs to $10^{-7} \mathrm{M}$ DEX for up to 14 days produced very few CLANs. In contrast, DEX induced abundant CLANs (Fig.3b) in BLC cells, which were evident at 3 days and were present in over $70 \%$ of cells by 14 days (Fig.4). A masked qualitative examination of our HLC cells indicated that DEX exposure also induced CLAN positive cells from 3 days onwards (Fig. 3c). However the steroid induction was more variable and less ranging from $35-50 \%$ of HLC cells. Without DEX, there was still evidence of a fairly high incidence of CLANs in confluent HLC cells (in the order of 20\%) that was particularly marked in cultures from glaucomatous donors (Fig.5).

In both species, many of the CLANs were fairly large structures (Fig. 3) and in the cells from the glaucoma patients the CLANs could be extremely large(Fig. 5). We considered "large" as having 20 or more hub points with the CLAN territories occupying one third or more of the total cytoplasm. The vast majority of the CLANs had the "classic" polygonal arrangements of hubs with delicate spokes radiating outwards from the central hub linked with adjacent hub(Figs.3b, $c$ and 5). The usual arrangement contained 5- 6 spokes per hub, and often the CLANs formed flattened geodesic dome or saucer-like arrangements over the apical surface of the nucleus. CLANs were often also found away from the nucleus but were never found beneath the nucleus. After removal of DEX from the culture medium, CLANs persisted in high numbers so that even by 10 days their incidence was significantly higher than baseline (Student's $t$-test; $\mathrm{P}<0.05$ ).

\section{DISCUSSION}

The cells of the LC surround the individual septae and also are embedded within the intra-laminar connective tissue of these structures. Irrespective of whether they were exposed to DEX or not, normal or glaucomatous, human or bovine, in situ or in tissue culture, LC cells or ONHAs, the 
dominant F-actin distribution pattern of cells was cytoplasmic bundles of actin filaments in the form of stress fibres. An abundance of stress fibres was present in all our human and bovine LC cells and ONHAs in culture, similar in appearance to those in all cultured TM cells we have investigated. $[13,20]$ Stress fibres have also been shown to be the dominant actin pattern in TM cells of the normal, glaucomatous, and DEX treated human outflow systems. [8-10] They are also prominent in the bovine outflow system[20]. Stress fibres have been studied more in cultured cells than in vivo, where they consist predominantly of F-actin cross-linked to alpha-actinin myosin II,[21] which imparts contractile properties to the cells.[22] Contraction of stress fibres takes place on a far more protracted time scale compared to muscle fibres[21] and it is thought to provide stiffness to cells[22] by increasing centripetal tension. In addition, stress fibres may well be mechanosensory. [23] Cyclical axial stretching of blood vessel endothelium[12,24] and TM cells[3] causes their stress fibres to realign parallel to the direction of stretch, indicating that these fibres have adhesive and protective roles.[25] It is likely that the stress fibres of LC cells have similar properties, and as such they would help resist (and even respond to) the biomechanical strains that occur in the normal and abnormal environment of the optic nerve head.[4,6] Given the known properties of stress fibres, an abundance of these actin-rich structures in LC cells seems to be entirely appropriate.

Careful systematic examination of the cells in the LC lamellae for actin patterns showed, in all the specimens examined, that some cells contained actin rich arrangements of geometrically arranged fluorescent dots (hubs) and filaments (spokes) that could be seen more clearly by reconstruction of sequential confocal images in a z-series. We were happy to call these structures CLANs even although they were smaller and less well organised than those found in tissue culture. These CLANlike arrangements were restricted to cells of the LC region and although our survey approach was exploratory rather than quantitative, we had the impression that these CLANs and actin aggregates were quite common in the LC tissue. Further on masked qualitative examination, there seemed to be a greater abundance of CLANs in DEX treated compared to untreated specimens. It is important to note that DEX effectively induces CLANs in TM cells, but it often takes up to 14 days for maximum effect both ex vivo[9] and in vitro[13,20]. In our LC study, our maximum exposure time could only be 7 days because of tissue degeneration in basic organ culture conditions, therefore that we could pick up a steroid effect at all was gratifying.

It is the case that the TM lends itself to confocal microscopic evaluation of cellular actin far more readily [8-10] than the LC tissue which is denser, less open and more difficult to conduct cellular analysis. In the human TM tissue, the cells are essentially aligned in a 2D arrangement on the trabeculae, which aids confocal imaging of sub-cellular structure. $[9,10]$ However, identification of CLANs gets more problematic in the juxtacanalicular (JCT) region where the cells are organised in a more complex 3D arrangement.[8] Also CLAN identification is problematic in the less well structured bovine TM when compared to the human TM.[20] Investigations in the TM predicted some of the imaging difficulties associated with the architecturally complex connective tissue septae of the optic nerve head and that turned out to be the case. At present it would seem that for an effective quantitative rather than qualitative approach we may need to modify our approach to allow for effective identification of CLANs in the LC tissue in situ.

We therefore attempted to identify CLANs in cultured LC cells in order to address some of the key comparative and quantitative questions raised by our tissue investigations. Our studies 
demonstrated that LC cells contain and can produce structures that are virtually identical to the CLANs of TM cells. Indeed, a surprisingly large proportion of both the human (up to about $20 \%$ with the incidence highest in cells from glaucoma donors) and bovine (5-10\%) LC cells had CLANs in their cytoplasm in normal culture conditions. Exposure to DEX increased CLAN incidence so that there was evidence of a steroid effect on LC cells of both human and bovine by as little as 3 days. The DEX responses were more variable and less pronounced for our normal HLC cells than the BLC cells, unlike the comparable curves for both human[13] and bovine[20] TM cells. In addition, CLANs in LC cells were remarkably similar in appearance to those in TM cells with the characteristic hub and spoke arrangement. The only differences we have noted so far is the tendency for LC cell CLANs to be located over the cell nucleus which is a much less common event in TM cells.

Human and bovine LC cell cultures have the full potential to produce CLANs in response to DEX exposure. In contrast, ONHAs do not appear to produce CLANs. Occasionally a CLAN was found in bovine ONHAs, especially after DEX treatment, but it was a rare event in a few cultures. We could not exclude the possibility that we were identifying a contaminating LC cell, since our standardised culture medium was not ideal for astrocyte growth.[15]

Overall we have now shown that CLANs are present in bovine and human LC cells. Together with TM cells, these are the only cell types which have been found [13] to reorganize their cytoskeleton to form CLANs with chronic corticosteroid exposure. The precise biological and patho-physiological significance of CLAN formation in terms of glaucoma is an active area of research. It is intriguing that these unique cytoskeletal structures are found in two of the major tissues that are associated with glaucomatous damage to the eye. We will pursue the very real possibility that changes in cytoskeletal actin, particularly CLAN formation, in the key cells of the optic nerve head and outflow system compromises their function in glaucoma.

\section{ACKNOWLEDGEMENTS}

The authors would like to acknowledge the generous support provided by Mid Cheshire Hospitals NHS Trust, The Guide Dogs for the Blind, Fight for Sight, Research into Ageing, The Foundation for Prevention of Blindness and an Unrestricted Grant from Alcon, Fort Worth. The authors would also like to thank Daniel Brotchie and Dr Kathy Cracknell for their help with this article.

\section{REFERENCES}

1. Johnstone MA, Grant WG. Pressure-dependent changes in structures of the aqueous outflow system of human and monkey eyes. Am J Ophthalmol. 1973;75:365-83.

2. Grierson I, Lee WR. The fine structure of the trabecular meshwork at graded levels of intraocular pressure:(1) Pressure effects within the near-physiological range $(8-30 \mathrm{~mm} \mathrm{Hg})$. Exp Eye Res. 1975;20:505-521.

3. Tumminia SJ, Mitton KP, Arora J, Zelenka P, Epstein DL, Russell P. Mechanical stretch alters the actin cytoskeletal network and signal transduction in human trabecular meshwork cells. Invest Ophthalmol Vis Sci. 1998;39:1361-1371.

4. Quigley H, Hohman R, Addicks E, Massof R, Green W. Morphological changes in the lamina 
cribrosa correlated with neural loss in open-angle glaucoma. Am J Ophthalmol. 1983;95:673691.

5. Kirwan RP, Fenerty CH, Crean J. Wardinger RJ, Clark AF, O'Brien CJ. Influence of cyclical mechanical strain on extracellular matrix gene expression in human lamina cribrosa cells in vitro. Mol. Vis. 2005;11:798-810.

6. Yang H, Downs JC, Sigal IA, Roberts MD, Thompson H, Burgoyne CF. Deformation of the normal monkey optic nerve head connective tissue following acute IOP elevation within 3-D histomorphometric reconstructions. Invest Ophthalmol Vis Sci. 2009;50:5785-5799.

7. Sigal IA, Ethier CR. Biomechanics of the optic nerve head. Exp Eye Res. 2009;88:799-807.

8. Read AT, Chan DWH, Ethier CR. Actin structure in the outflow tract of normal and glaucomatous eyes. Exp Eye Res. 2006;82:974-985.

9. Clark AF, Brotchie D, Read AT, et al. Dexamethasone alters F-actin architecture and promotes cross-linked actin network formation in human trabecular meshwork tissue. Cell Motil Cytoskeleton. 2005;60:83-95.

10. Hoare MJ, Grierson I, Brotchie D, Pollock N, Cracknell K and Clark AF. Cross-Linked Actin Networks (CLANs) in the trabecular meshwork of the normal and glaucomatous human eye in situ. Invest Ophthalmol Vis Sci 2009;5:1255-63

11. Steely T, English-Wright SL, Clark AF. The similarity of protein expression in trabecular meshwork and lamina cribrosa: Implication for glaucoma. Exp Eye Res. 2000;70:17-30.

12. Kaunas R, Hsu H-J. A kinematic model of stretch-induced stress fiber turnover and reorientation. J Theor Biol. 2009;257:320-330.

13. Clark AF, Wilson K, McCartney MD, Miggans ST, Kunkle M, Howe W. Glucocorticoid-induced formation of cross-linked actin networks in cultured human trabecular meshwork cells. Invest Ophthalmol Vis Sci. 1994;35:281-294.

14. Balaratnasingam C, Morgan WH, Johnstone V, Cringle SJ, Yu D-Y. Heterogeneous distribution of axonal cytoskeleton proteins in the human optic nerve. Invest Ophthalmol Vis Sci. 2009;50:2824-2838.

15. Hernandez MR. The optic nerve head in glaucoma: role of astrocytes in tissue remodeling. Prog Ret Eye Res. 2000;19:297-321.

16. Wax MB, Tezel G, Kobayashi S, Hernandez MR. Responses of different cell lines from ocular tissues to elevated hydrostatic pressure. Br. J Ophthalmol. 2000;84:423-428.

17. Huang $X R$, Knighton RW. Altered F-actin distribution in retinal nerve fiber layer in a rat model of glaucoma. Exp Eye Res. 2009;88:1107-1114.

18. Hernandez MR, Igoe F, Neufeld AH. Cell culture of the human lamina cribrosa. Invest Ophthalmol Vis Sci. 1988;29:78-89.

19. Lambert W, Agarwal R, Howe W, Clark AF, Wordinger RJ. Neurotrophin and neurotrophin receptor expression by cells of the human lamina cribrosa. Invest Ophthalmol Vis Sci. 2001;42:2315-2323. 
20. Wade N, Grierson I, O'Reilly S, Hoare M J, Cracknell K, Paraoan L, Brotchie D, Clark AF. Cross linked actin networks in bovine trabecular meshwork cells. Exp Eye Res. 2009;89:648-659.

21. Naumanen $P$, Lappalainen $P$, Hotulainen $P$. Mechanisms of actin stress fibre assembly. J Microscopy.2008;231:446-454.

22. Lu L, Oswald SJ, Ngu H, Yin FCP. Mechanical properties of actin stress fibers in living cells. Biophys J. 2008;95:6060-6071.

23. Colombelli J, Besser A, Kress H, Reynauld EG, Girard P, Caussinus E, Haselman JV, Small JV, Schwarz US, Stelzer EHK. Mechanosensing in actin stress fibers revealed by a close correlation between force and protein localization. J Cell Sci. 2009;1665-1679.

24. Sipkema P, van der Linden PJ, Westerh of N, Yin FC. Effect of cyclic axial stretch of rat arteries on endothelial cytoskeletal morphology and vascular reactivity. J Biomech. 2003;36:653-659.

25. Chien S. Molecular basis of rheological modulation of endothelial functions: importance of stress direction. Biorheol. 2006;43:95-116. 


\section{Legends}

Fig.1 Part of the optic nerve head and a cross section of the central vessels (CV) by

immunofluorescence microscopy with (a) phalloidin-Alexa 488 staining for F-actin and (b) PI staining for nuclei. It can be seen that the lamina cribrosa (LC) stains intensely for F-actin when compared to the prelaminar (PL) and retrolaminar (RL) tissue.

Fig.2 Confocal microscopy of cells within the connective tissue septae of the LC. In (a) cytoplasmic Factin rich stress fibre bundles (white arrows) are shown. (b) By phalloidin staining it was difficult to clearly identify the hub and spoke arrangement of CLANs which tended to be small (usually less than $10 \mu \mathrm{m}$ maximum diameter) but in a few of the larger ones (as with this example (white circle)) the hub and spoke arrangement was evident. (c) Following alpha-actinin staining the pattern seen is of small fluorescent dots but occasionally we find aggregates of dots ranging in diameter from a few $\mu \mathrm{m}$ up to $20 \mu \mathrm{m}$ (as with this example) which is the size range of the structures we call CLANs.

Fig.3 Confocal microscopy of BLC cells from confluent cultures that are grown from GFAP negative primaries and which are stained with phalloidin-Alexa 488 (a) and with phalloidin-Alexa 488 and PI (b). In (a) the dominant cytoplasmic stress fibre pattern is evident in a group of confluent cells not exposed to DEX. In (b) the cells have been exposed to DEX for up to 14 days. At 14 days stress fibres are still present but also CLANs are prominent in many of the cells. They have a clear hub and spoke arrangement such that each unit of the CLAN is a polygonal arrangement with 5 to 6 spokes radiating from each hub. In addition the CLANs seem to be preferentially located in the cytoplasm over the nucleus. In (c) A CLAN in a HLC cell at 3 days exposure to DEX. The same polygonal arrangement of hubs and spokes as in BLC CLANs is seen.

Fig.4 The graph shows the base line incidence of CLANs in BLC cells from confluent cultures that are grown from GFAP negative primaries and have (solid line) or have not (dotted line) been exposed to DEX, figure shows means and standard deviations. At all time periods from three days onwards the incidence of CLANs in the DEX treated cultures was significantly higher (Student's t- test) and reached an incidence of around $70 \%$ or more by the maximum period of exposure of 14 days.

Fig.5 Epifluorescence microscopy of HLC cells from confluent cultures that were grown from the LC from a patient with primary open angle glaucoma. The cells were stained with phalloidin-Alexa 488 and CLANs were common in these cultures even in the absence of DEX. Stress fibres were abundant. A large CLAN is shown and is indicated by arrows and it is surrounded by stress fibres. 






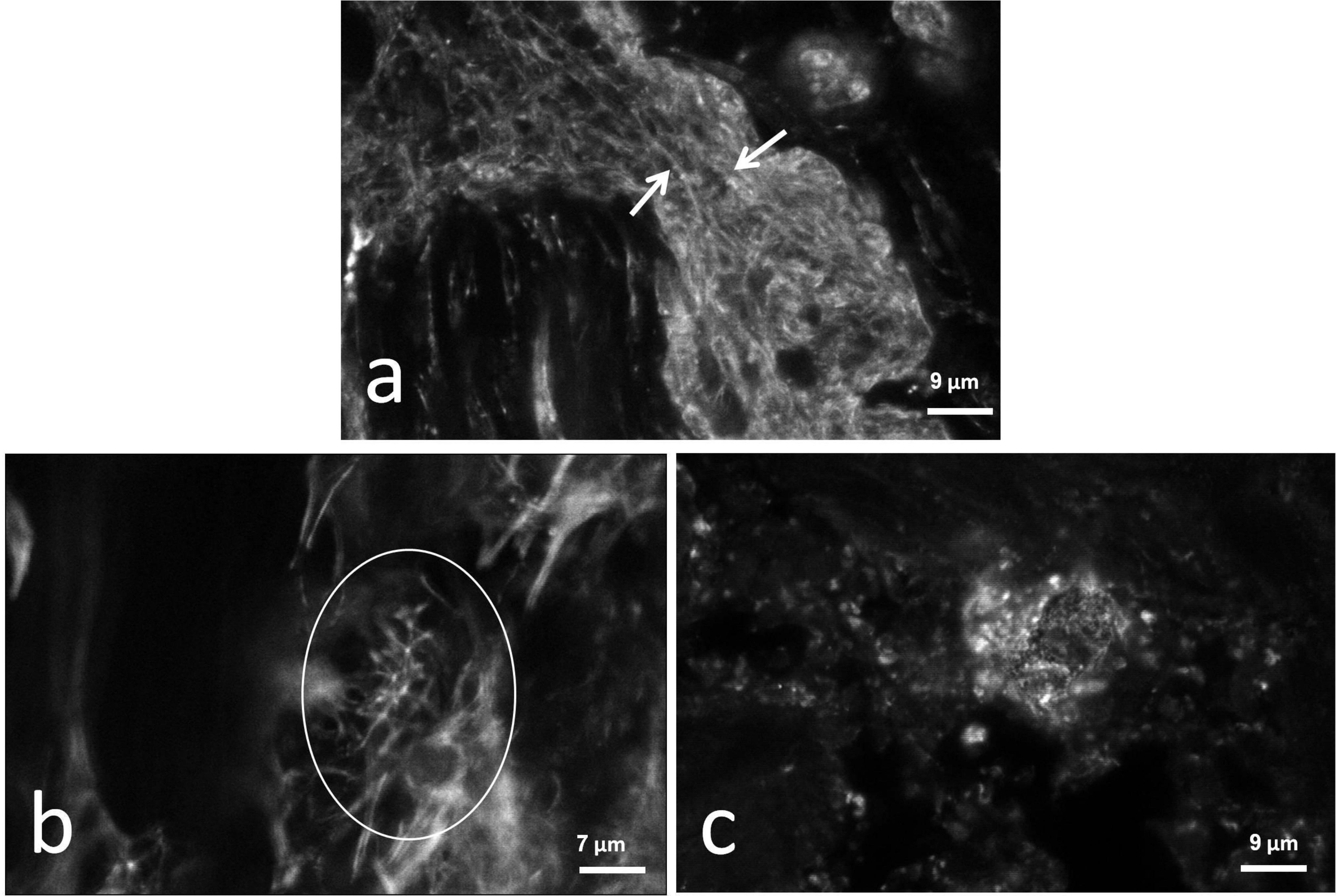


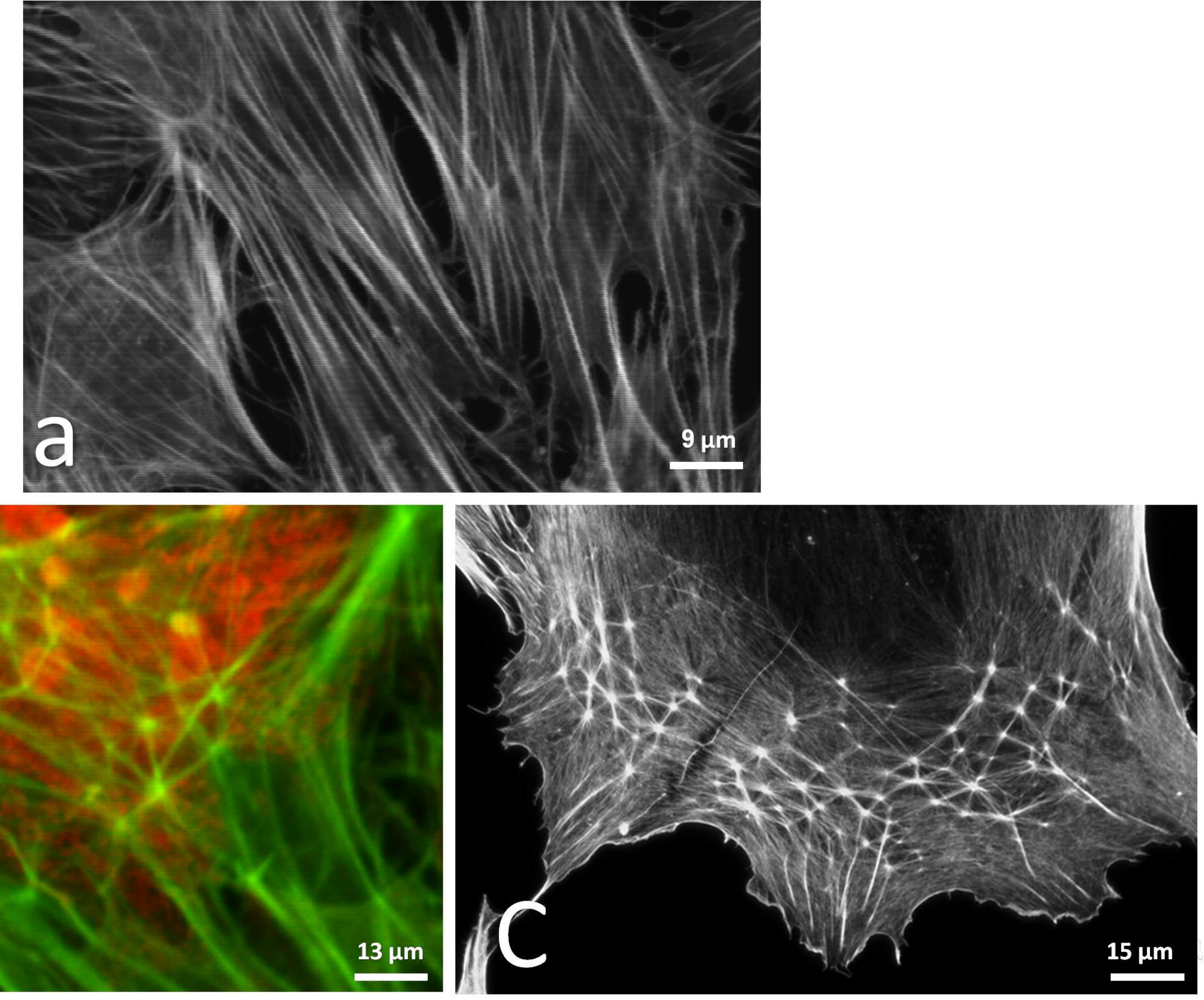




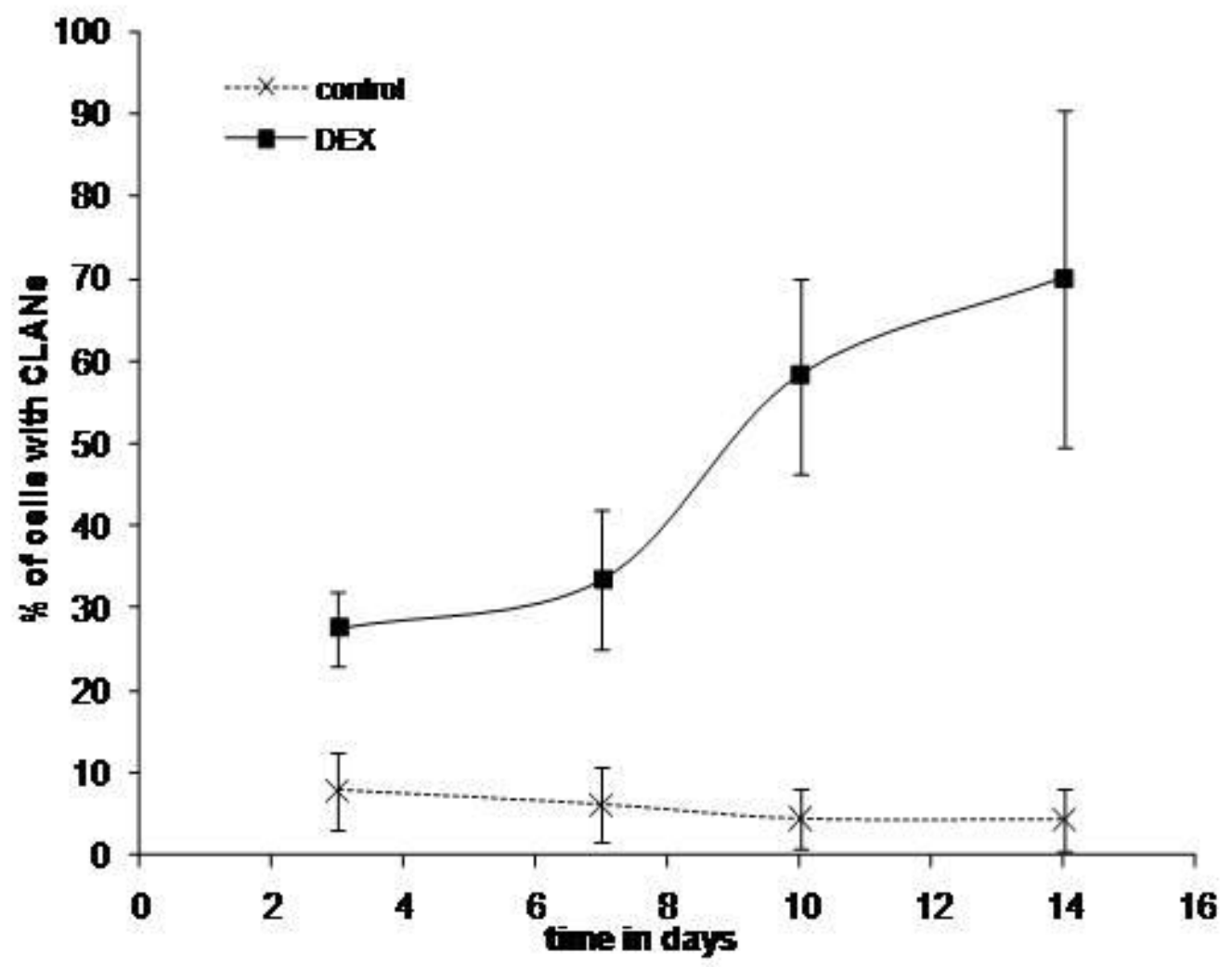




\section{$\leftarrow$}

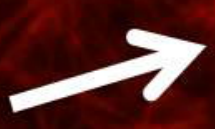

